\title{
Políticas y prácticas de ordenamiento territorial en América Latina
}

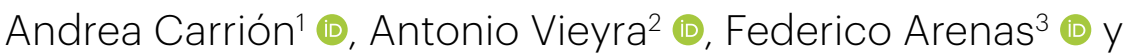 \\ Voltaire Alvarado 4
}

En América Latina, las políticas de ordenamiento territorial (OT) se han revalorizado de manera paulatina desde los años ochenta junto con otros procesos de planificación del desarrollo. La inclusión de la perspectiva geográfica en la planeación buscaba revertir inequidades estructurales, reducir conflictos en el uso y ocupación del suelo, impulsar la conservación ambiental, orientar el crecimiento urbano y corregir los desequilibrios territoriales que afectan la competitividad sistémica y la cohesión social (Buitelaar et al., 2015; Montes-Lira, 2001; Massiris, 2006; Irazábal, 2009) y que de forma creciente está adquiriendo la atención de analistas y de tomadores de decisión. La implementa- ción de políticas nacionales que propicien la convergencia territorial y que logren un desarrollo territorial equilibrado, sustentable e incluyente, se hace cada vez más nece- sario para el progreso de los países. El nuevo interés por la dimensión territorial del desarrollo a nivel de las agendas nacio- nales, visible con mayor nitidez desde comienzos de los 2000, tiene como fundamento un conjunto de factores objetivos que han emergido en la última década y que requie- ren de una aproximación territorial más explícita desde el nivel nacional de las políti- cas públicas. Entre ellos pueden mencionarse los desafíos en materia de desigualda- des sociales, de competitividad territorial y de sustentabilidad ambiental. Es con este propósito que EUROsociAL, en conjunto con el ILPES, se encuentran traba- jando en la sistematización y análisis del estado actual de las estrategias, planes o po- líticas nacionales de desarrollo territorial en América Latina y el Caribe, con el propósi- to de colaborar con los países de la región en sus procesos de diálogo y cooperación sur-sur y de cooperación entre la Unión Europea y América Latina. Para estos efectos se elaboraron un conjunto de estudios que abordaron dos grandes temas: a. En este escenario, la gestión del territorio pasó a ser un elemento clave de la política pública para la gobernanza pluritemporal, multiescalar e intersectorial del desarrollo (Máttar \& Cuervo 2017).

La planificación territorial se posicionó como un mecanismo de articulación y coordinación -vertical y horizontal- en un contexto de descentralización y desconcentración. Sin embargo, las políticas nacionales de ordenamiento territorial se confrontaron con marcos legales, arreglos administrativos y sistemas de planificación en proceso de consolidación, con competencias, instrumentos y capacidades definidas en los diversos niveles de gobierno (REDEPLAN, 2015).

Coordinadora del proyecto "Construyendo liderazgo para las ciudades de América Latina y el Caribe en un clima cambiante" (FLACSO-IDRC), Facultad Latinoamericana de Ciencias Sociales, FLACSO Ecuador. Correo electrónico: acarrionh@flacso.edu.ec

Investigador titular, Director del Centro de Investigaciones en Geografía Ambiental, Universidad Nacional Autónoma de México. Correo electrónico: avieyra@ciga.unam.mx

Profesor titular, Director del Instituto de Geografía, Pontificia Universidad Católica de Chile. Correo electrónico: farenasv@uc.cl

Profesor, Departamento de Geografía, Universidad de Concepción, Chile. Correo electrónico: voalvarado@udec.cl 
Massiris (2006) identifica tres tendencias predominantes en los países de la región: la planificación física con énfasis urbanístico o municipal; la planificación física con énfasis ambiental en lo relativo al uso de recursos naturales, la protección ambiental y la prevención de desastres; y el enfoque de planificación socioeconómica con énfasis en la noción de desarrollo económico territorial. En ciertos países se observan sistemas nacionales que incorporan al ordenamiento territorial de manera transversal como un componente integral de la planificación estatal. Más allá de esta clasificación, las tensiones en los proceso de planeación urbana, ecológica, económica y administrativa revelan la multiplicidad de aproximaciones a instrumentos de política pública en permanente reconstrucción.

De manera más reciente, la perspectiva espacial también cobra importancia como un elemento para la implementación de acuerdos globales como la Agenda 2030 y los Objetivos de Desarrollo Sustentable (CEPAL, 2019). Ello supuso una nueva movilización de conocimientos, información y recursos procedentes de diversos actores, entre los que se encuentran los organismos multilaterales, la cooperación internacional y las entidades públicas nacionales, con una mayor circulación de experiencias Sur-Sur (Porto de Oliveira, 2020; Jajamovich \& Delgadillo, 2020). A su vez, se ha incrementado significativamente la difusión y circulación de herramientas y propuestas para la planificación territorial, particularmente en lo relativo a instrumentos o técnicas para la gestión del desarrollo urbano (Leite et al., 2020).

La distancia entre los procesos reales de producción material del territorio y las representaciones abstractas del territorio, creadas a través de procesos de planificación institucionalizada, ha dado paso a nuevas formas de planificación insurgente, participativa y ciudadana, impulsadas desde una perspectiva crítica que busca recuperar la autonomía local en la gestión del territorio. En este contexto, existen cuestionamientos al ordenamiento territorial como un instrumento que formaliza espacios jurídico-políticos que reproducen procesos estructurales de violencia, dominación y explotación (Silveira et al., 2017; Yiftachel, 1998)which reaffirms the collective rights of indigenous peoples and recognizes nature as a subject of rights. However, in order to finally realize the postponed capitalist modernization, the current government chose to deepen the development model based on the extraction and export of raw materials. This model requires a territorial ordering that defines "spaces of sacrifice" for the national good. This means "socially emptyable" areas (Svampa 2011; como parte de un proceso inducido por la globalización y modernización flexible que crea, a su vez, nuevas formas de territorialidad (Haesbaert, 2007). Así, los procesos de planificación impulsados por el sector público han sido criticados por su mirada jerárquica y tecnocrática, que favorece una lógica capitalista pero desconoce las identidades locales y la territorialidad de los pobladores urbanos o las comunidades indígenas y campesinas.

En definitiva, un elemento distintivo de este milenio es la sobreabundancia de iniciativas, metodologías y planes territoriales -muchas veces contradictorios, superpuestos o inalcanzablesque reconfiguran las relaciones de poder para la apropiación social de espacio (Villagómez et al., 2020). Es decir, la planificación territorial sigue siendo un concepto polisémico y un instrumento de gestión de carácter técnico-político-administrativo con connotaciones en su implementación en diversos espacios geográficos. La capacidad de interlocución entre las autoridades políticas, los analistas técnicos, los gestores públicos y los actores en el territorio continúa siendo un desafío para la adopción y operativización de las propuestas participativas orientadas a una efectiva transformación de inequidades hacia una mayor justica socio-espacial. 


\section{El presente número}

Este número temático de la Revista de Geografía Norte Grande tiene por objetivo central debatir sobre las racionalidades, las políticas, las metodologías y las prácticas para la planificación y el ordenamiento territorial en América Latina. El volumen presenta 20 artículos, de los cuales trece corresponden al tema central organizado en cuatro secciones. Durante el proceso de selección y evaluación, se privilegiaron aquellos artículos sustentados en casos concretos, con un enfoque dialéctico que pudieran reconocer los avances programáticos y las brechas de implementación.

El primer grupo de artículos explora los marcos legislativos y las estructuras institucionales para la gobernanza territorial, la coordinación sectorial y la articulación multinivel de la planificación, resaltando el enfoque administrativo del ordenamiento territorial. En ocasiones, las clasificaciones jurídicas proclaman una apropiación reglamentaria del espacio más allá de las dinámicas territoriales.

El artículo "Marcos legislativos, racionalidades político-económicas y ordenamiento territorial: La desarticulación sectorial y multinivel en México" resalta las tensiones que surgen entre las racionalidades político-económicas y el desarrollo territorial equilibrado, en donde la sectorización normativa y la desarticulación multinivel entorpecen las políticas de ordenamiento territorial en México. Es importante denotar las racionalidades de gobierno, las relaciones de poder y los intereses ocultos que subyacen los razonamientos de los actores, entre ellos legisladores, funcionarios y servidores públicos en la producción y aplicación de leyes e instrumentos de OT. En este caso, la asimilación de políticas neoliberales que instan a territorios inteligentes, innovadores y competitivos, desde un enfoque de gestión empresarial, limita que el OT se consolide como un instrumento de justicia redistributiva para la gestión democrática del territorio en diferentes niveles y escalas geográficas.

El artículo "Ordenamiento territorial en Chile: nuevo escenario para la gobernanza regional" analiza la incidencia de la descentralización política, administrativa y fiscal para el ejercicio de la gobernanza regional del ordenamiento territorial en Chile. El ordenamiento del territorio supone un ejercicio técnico con objetivos políticos que se confronta con los desafíos del traspaso de atribuciones, competencias y facultades de planificación a gobiernos regionales y municipalidades. En este caso, la regulación de usos del suelo se ve limitada por las decisiones presupuestarias y de inversión pública, en donde la lógica de financiamiento adquiere una connotación sectorial.

En esta misma línea, el artículo "La frustrada construcción de la "región" en el Ecuador (20072017): lecciones y perspectivas" analiza el proceso de regionalización político-administrativa en Ecuador como un frustrado intento de atenuar o compensar las disparidades territoriales, que buscaba crear un nuevo nivel intermedio de gobierno a partir de criterios asociados a la funcionalidad espacial. La visión institucionalista y la racionalidad tecnocrática se confrontaron con una reorientación de la política nacional y la historicidad de los procesos de gobernanza territorial, limitando su implementación a un acto performativo del gobierno central.

El segundo grupo de artículos explora los paradigmas, los actores y los mecanismos que producen una geografía relacional para la circulación de ideas y propuestas de planificación territorial, incluyendo la localización de compromisos internacionales a través de instrumentos de política pública. Con base en la ciudad de Córdoba, el artículo "Las agendas internacionales y el desarrollo urbano local. Una revisión por los modelos de planificación e instrumentos adoptados por la gestión urbana local en Córdoba, Argentina (1983-2019)" expone los conceptos y modelos 
difundidos por organismos internacionales para influenciar la gestión, políticas y planificación urbana. Las agendas globales han fomentado ideologías modernistas para orientar la gestión del territorio a través de metas, objetivos, lineamientos y buenas prácticas impulsadas por expertos, técnicos, burócratas y políticos. En cada etapa, existen perspectivas ideológicas que subyacen las distintas opciones de instrumentos, mecanismos y escalas de intervención urbana.

El artículo "De modelos internacionales y adaptaciones locales. El proceso de movilidad de la política de distritos económicos de la ciudad de Buenos Aires (2008-2019)" explora la circulación de conceptos asociados al "nuevo urbanismo" que promueven la innovación, la creatividad y la competitividad territorial en Buenos Aires. La propuesta de distritos tecnológicos y clusters, que favorecen las economías de aglomeración y la inserción de la ciudad en la economía mundial, incluyen un entramado enunciativo de actores que dan sustento a las políticas a partir de un ethos emprendedor. En este caso, la intervención urbanística despliega de manera simultánea discursos e instrumentos para la reestructuración de los territorios estratégicos en escalas múltiples e interconectadas.

El texto "¿Qué hay detrás de las intervenciones urbanas? Elementos históricos para develar las racionalidades urbanísticas en Chile" propone identificar los elementos contextuales, teóricos y prácticos que están detrás de las intervenciones urbanas durante el siglo XX en Chile. Se argumenta que los patrones de acumulación capitalista circunscriben las racionalidades urbanísticas, al tiempo que la tecnificación y diversificación de herramientas de diagnóstico e intervención despolitiza la gestión urbana.

Para comprender las racionalidades de planeación, el tercer grupo de artículos profundiza en ciertas prácticas y técnicas que han adquirido relevancia en la última década. El artículo "Vivienda sin ciudad, ciudad sin planificación, planificación sin habitantes: APP para la reconstrucción territorial post-desastre" describe a la reconstrucción iniciada luego del terremoto de febrero de 2010 en la ciudad de Constitución como una opción para innovar en la gestión del territorio a partir de alianzas público-privadas, que sin embargo se enfrenta a racionalidades tecnocráticas, intereses privados y deficiencias de las políticas urbanas regulares. En este caso, la disociación entre la tecnocracia urbana y la experiencia de los habitantes mantiene y refuerza el paradigma neoliberal ya existente.

En contraposición, el artículo "De ciudadanías insurgentes a planificadores, urbanos. Organización social en la urbanización del campamento Manuel Bustos de Viña del Mar" expone la experiencia del campamento Manuel Bustos de Viña del Mar, donde la organización comunitaria permitió revalorizar la trayectoria de producción social del hábitat y disputar la materialización del derecho a una vivienda digna. En este caso, el empoderamiento de los dirigentes, con capacidad de diálogo político, constituye un ejemplo de ciudadanía insurgente y activa para quebrar la lógica top-down para la producción de vivienda de interés social.

El artículo "Vinculación entre el Ordenamiento Territorial y la gestión del agua en Argentina y en la provincia de Buenos Aires. Análisis de aspectos normativos e institucionales (2003-2019)" aborda la importancia de una articulación intersectorial entre políticas públicas para gestión integrada de los recursos hídricos y el ordenamiento territorial en Buenos Aires. Los autores señalan que pese a los avances en los momentos técnico-científico y técnico-político dentro del ciclo de políticas, existe una falta de conexión formal que permita el diseño de instrumentos o acciones concretas tendientes a lograr esta vinculación a nivel institucional, administrativa o normativa. 
Los autores del artículo "Cambio Climático adverso provocado por la urbanización sin planificación ni evaluación ambiental en Santiago de Chile" denotan la paradoja entre la ocurrencia de fenómenos climáticos extremos, la ausencia de variables climáticas críticas para la planificación urbana, y la adhesión retórica a acuerdos internacionales para la mitigación y adaptación al cambio climático en Santiago. En Chile, el clima y el aire son bienes y servicios comodificados cuyo acceso depende de la capacidad adquisitiva de la población. Para superar esta condición, abogan por la inclusión de variables técnicas y soluciones basadas en la naturaleza como elementos orientadores para la transformación morfológica y la gestión ambiental de la ciudad.

Finalmente, el cuarto grupo de artículos profundiza los debates que posicionan a la planificación territorial como una herramienta de articulación entre el régimen de acumulación, el desarrollo económico y la regulación del uso del suelo.

El artículo “¿Esmeraldas indomable? La planificación urbana a la luz de los regímenes de acumulación" señala que la estructuración del territorio en Esmeraldas, Ecuador, es el resultado de dinámicas económicas multiescalares que crean una paradoja entre el carácter estratégico de las instalaciones petroleras y la precariedad de la ciudad informal. El trabajo enfatiza que la construcción social de los riesgos urbanos deviene de una relación asimétrica entre actores sociales, en donde la inversión pública incrementa la vulnerabilidad territorial y la planificación modernizadora es reactiva a la realidad material.

El artículo "Ordenamiento y gestión del territorio en zonas costeras con turismo residencial. El caso de Región Este, Uruguay" reconoce los efectos territoriales, el impacto acumulativo y la fragmentación socioespacial derivada del rentismo inmobiliario y el turismo residencial costero en Uruguay. En este caso, la normativa relativa a estudios de impacto ambiental se aplica de manera parcial o incompleta, lo que refuerza la apropiación de las playas por parte de los propietarios con mayor poder adquisitivo.

El artículo "Fronteira, direitos humanos e territórios tradicionais em Rondônia (Amazônia Brasileira)" denuncia la expropiación, la violencia y el crimen ambiental asociado a la expansión espacial del capital en regiones periféricas de la Amazonía brasilera. Se argumenta que los espacios institucionalizados de planificación estatal apoyan las actividades extractivas de los grupos económicos, en detrimento de los derechos humanos y territoriales de los pueblos indígenas.

Como tema transversal se exploran las resistencias, abandonos y alternativas a la planificación y el ordenamiento territorial por parte de organizaciones y movimientos sociales. Ciertamente, uno de los mayores desafíos del ordenamiento territorial es la integración efectiva de la ciudadanía, para habitar y producir territorios inclusivos, a partir de un urbanismo situado.

Termina esta entrega con los trabajos regulares de la Revista de Geografía Norte Grande, a la que este Comité Editorial invitado agradece, tanto en la gestión como en la posibilidad de entregar estas investigaciones.

\section{Bibliografía}

BUITELAAR, R.M, ECHEVERRI PERICO, R., SILVA LIRA, I. \& RIFFO PÉREZ, L. Estrategias y políticas nacionales para la cohesión territorial. Estudios de caso latinoamericanos. Santiago de Chile: CEPAL, 2015. 
CEPAL. La dimensión territorial en el marco de la Agenda 2030 para el Desarrollo Sostenible Guía metodológica para la planificación estrategica de un territorio. Documentos de Proyectos (LC/ TS.2019/58). Santiago de Chile: Comisión Económica para América Latina y el Caribe (CEPAL), 2019.

HAESBAERT, R. Território e multiterritorialidade: um debate. GEOgraphia, 2007, Vol. 9, №17, p. 19-46.

IRAZÁBAL, C. Revisiting Urban Planning in Latin America and the Caribbean. Global Report on Human Settlements, №49, 2009. Disponible en https://academiccommons.columbia.edu/ doi/10.7916/D85M6BHX (18 de octubre de 2020)

JAJAMOVICH, G. \& DELGADILLO, V. The circulation of knowledge and urban policies in Latin America. Introduction. Iberoamericana, 2020, Vol. 20, N74, p. 7-11.

LEITE, C, ACOSTA, C. MILITELLI, F., JAJAMOVICH, G., WILDEROM, M., BONDUKI, N., SOMEKH, N. \& HERLING, T. Social Urbanism in Latin America. Cases and Instruments of Planning, Land Policy and Financing the City Transformation with Social Inclusion. Suiza: Springer, 2020.

MASSIRIS, A. Políticas latinoamericanas de ordenamiento territorial: Realidad y desafíos. Bogotá: Universidad Nacional de Colombia, 2006.

MÁTTAR, J. \& CUERVO, L.M. Planificación para el desarrollo en América Latina y el Caribe: enfoques, experiencias y perspectivas. Santiago de Chile: CEPAL, 2017.

MONTES-LIRA, P. El ordenamiento territorial como opción de políticas urbanas y regionales en América Latina y el Caribe. Medio Ambiente y Desarrollo. Santiago de Chile: CEPAL, 2001.

PORTO DE OLIVEIRA, O. 2020. Comparing international policy transfers. En: GUY PETERS, B. \& FONTAINE, G. (eds.). Handbook of Research Methods and Applications in Comparative Policy Analysis. Cheltenham: Edward Elgar Publishing, 2020, p. 134-151.

REDEPLAN. Diagnóstico de los Sistemas de Planificación de la Región. Documentos de trabajo 2013-2015. Quito: Red de América Latina y el Caribe de Planificación para el Desarrollo-REDEPLAN, 2015.

SILVEIRA, M., MOREANO, M., ROMERO, N., MURILLO, D., RUALES, G. \& TORRES, N. Geografías de sacrificio y geografías de esperanza: tensiones territoriales en el Ecuador plurinacional. Journal of Latin American Geography, 2017, Vol. 16, №1, p. 69-92.

VILLAGÓMEZ, M., CUESTA, R., SILI, M. \& VIEYRA, A. Metodología para el análisis de las prácticas y políticas de ordenamiento territorial en América Latina: el caso de Argentina, Ecuador, México y Paraguay». Revista Geográfica, 2020, №160, p. 57-89.

YIFTACHEL, O. Planning and social control: exploring the dark side. Journal of Planning Literature, 1998, Vol. 12, N4, p. 395-406. 